\title{
Bulbomembranous Urethral Malignant Neoplasm
}

National Cancer Institute

\section{Source}

National Cancer Institute. Bulbomembranous Urethral Malignant Neoplasm. NCI

Thesaurus. Code C39869.

A malignant neoplasm that affects the bulbomembranous part of the urethra. 